\title{
Correction to: Thermomechanics \& Infrared Imaging, Inverse Problem Methodologies and Mechanics of Additive \& Advanced Manufactured Materials, Volume 7
}

Sharlotte L. B. Kramer and Rachael Tighe

\section{Correction to:}

S. L.B. Kramer, R. Tighe (eds.), Thermomechanics \& Infrared Imaging, Inverse Problem Methodologies and Mechanics of Additive \& Advanced Manufactured Materials, Volume 7, Conference Proceedings of the Society for Experimental Mechanics Series, https://doi.org/10.1007/978-3-030-59864-8

This book was inadvertently published with the incorrect spelling of the second editor's first name. The first name was incorrectly published as "Rachel" instead of "Rachael".

This has now been amended throughout the book. 